RESEARCH REPORT

\title{
Has the relation between income inequality and life expectancy disappeared? Evidence from Italy and top industrialised countries
}

\section{Roberto De Vogli, Ritesh Mistry, Roberto Gnesotto, Giovanni Andrea Cornia}

J Epidemiol Community Health 2005;59:158-162. doi: 10.1136/jech.2004.020651

See end of article for authors' affiliations

Correspondence to: Dr R De Vogli, Department of Epidemiology and Public Health, University College of London (UCL), London WCIE 6BT, UK; devogli@libero.it

Accepted for publication 28 April 2004

\begin{abstract}
Objective: To investigate the relation between income inequality and life expectancy in ltaly and across wealthy nations.

Design and setting: Measure correlation between income inequality and life expectancy at birth within Italy and across the top 21 wealthy countries. Pearson correlation coefficients were calculated to study these relations. Multivariate linear regression was used to measure the association between income inequality and life expectancy at birth adjusting for per capita income, education, and/or per capita gross domestic product.

Data sources: Data on the Gini coefficient (income inequality), life expectancy at birth, per capita income, and educational attainment for Italy came from the surveys on Italian household on income and wealth 1995-2000 and the National Institute of Statistics information system. Data for industrialised nations were taken from the United Nations Development Program's human development indicators database 2003. Results: In Italy, income inequality $(\beta=-0.433 ; p<0.001)$ and educational attainment $(\beta=0.306$; $p<0.001)$ were independently associated with life expectancy, but per capita income was not $(\beta=0.121$; $\mathrm{p}>0.05)$. In cross national analyses, income inequality had a strong negative correlation with life expectancy at birth $(r=-0.864 ; p<0.001)$.

Conclusions: In Italy, a country where health care and education are universally available, and with a strong social safety net, income inequality had an independent and more powerful effect on life expectancy at birth than did per capita income and educational attainment. Italy had a moderately high degree of income inequality and an average life expectancy compared with other wealthy countries. The cross national analyses showed that the relation between income inequality and population health has not disappeared.
\end{abstract}

have been proposed to explain away the effect of income inequality on health: per capita income and educational attainment. Gravelle argued that the relation between income inequality and mortality is an artefact of the nonlinear relation between income and mortality at the individual level. ${ }^{19}$ However, it is precisely the non-linear relation between micro-level income and life expectancy at birth that justifies the inclusion of income inequality in the study of mortality at the macro-level, for example, when making cross national comparisons. ${ }^{1}$ Later, Wolfson and colleagues $^{20}$ using multilevel analyses provided substantial evidence for a non-artefactual explanation..$^{21}{ }^{22}$ Others still maintain that population health measured by life expectancy does not depend on how income is distributed, but individual level income instead. ${ }^{16}{ }^{17} 23$

With regard to educational attainment, Muller using cross sectional data on income inequality and age adjusted mortality in the US concluded that the proportion of adults with high school diploma in a population accounts for the income inequality effect. ${ }^{24}$ These findings have been subsequently augmented with data from Brazil, which showed that the introduction of illiteracy into the analysis explained away the association between life expectancy and income inequality. ${ }^{25}$

In summary, many questions remain unanswered about whether and why there is an association between income inequality and health outcomes, which require further evidence from a variety of social, economic, and political contexts. If the relation between income inequality and health varies according to characteristics specific to place, it is
As results on the relation between income distribution and health outcomes have been inconsistent, previous evidence has been dismissed as spurious. At least two major factors 
of great interest to investigate such association in different nations. To date, we are not aware of studies that have undertaken this research in Italy, a country characterised by large regional differences in per capita income and income inequality, for example, the relative affluence of the north as compared with the south of Italy. ${ }^{26}$

In this research, we analysed the relation between the Gini coefficient and life expectancy at birth using aggregated data for all 20 Italian regions. We also examined whether or not this association is the result of variation in per capita income and educational attainment. Finally, we place the Italian data within an international context by studying the relation between income inequality and life expectancy at birth across top 21 industrialised countries.

\section{METHODS \\ Italy}

Data on life expectancy at birth for the year 2001, the study dependent variable, were extracted from the Italian National Institute of Statistics information system. ${ }^{27}$ The Gini coefficient was calculated using pooled data from the surveys on Italian household on income and wealth (SIHIW) conducted by the Bank of Italy in $1995(\mathrm{n}=8135), 1998(\mathrm{n}=7147)$, and $2000(\mathrm{n}=8001)$. Pooling of the three surveys was performed to assure a sample of at least 1000 subjects for 11 regions and at least 500 subjects for the remaining nine regions. ${ }^{28}$ Face to face interviews of household members were conducted. The sampling strategy consisted in two stages: firstly, a random sample of 300 municipalities (stratified by region and county size) was selected; secondly, a random sample of Italian households was drawn within each municipality. Poststratification adjustment or raking was used to assure that regional samples were similar to the general population in terms of sex, age, occupation, educational attainment, and municipality size. A more detailed description of the sampling methodology is discussed elsewhere. ${ }^{26}$

Covariates for the within Italy analysis included per capita income and educational attainment for each Italian region. Data on per capita income for each Italian region came from the SIHIW conducted in $2000 .{ }^{28}$ Using data from the National Institute of Statistics, we measured educational attainment as the proportion of persons 19 years old in each Italian region that obtained a high school diploma as of $1997 .{ }^{29}$ Data on population size, life expectancy at birth, educational attainment, per capita income, and Gini coefficients across Italian regions are shown in table A (see appendix, available on line http://www.jech.com/supplemental).

\section{Cross national}

Data on life expectancy at birth for the year 2001, Gini coefficient (data were available for different years-that is, from 1990 to 1998), and per capita gross domestic product (GDP) for Italy and the other 20 industrialised countries included in this study were taken from the United Nations Development Program's human development indicators published in $2003 .^{30}$ Countries selected for the analysis were the top 25 nations in terms of per capita GDP-Australia, Belgium, Canada, Denmark, Finland, France, Germany, Greece, Italy, Japan, Luxembourg, Netherlands, New Zealand, Norway, Portugal, Singapore, Spain, Sweden, Switzerland, UK, and USA-excluding Austria, Ireland, Israel, and Slovenia. Austria was excluded because income inequality data were not available. Ireland, Israel, and Slovenia were excluded because of their social instability and conflicts. Data on the Gini coefficient were calculated using per capita income as a living standard indicator and came from nationally representative household surveys using similar methodologies. The Gini coefficient was adjusted for household size, providing a more consistent measure of per
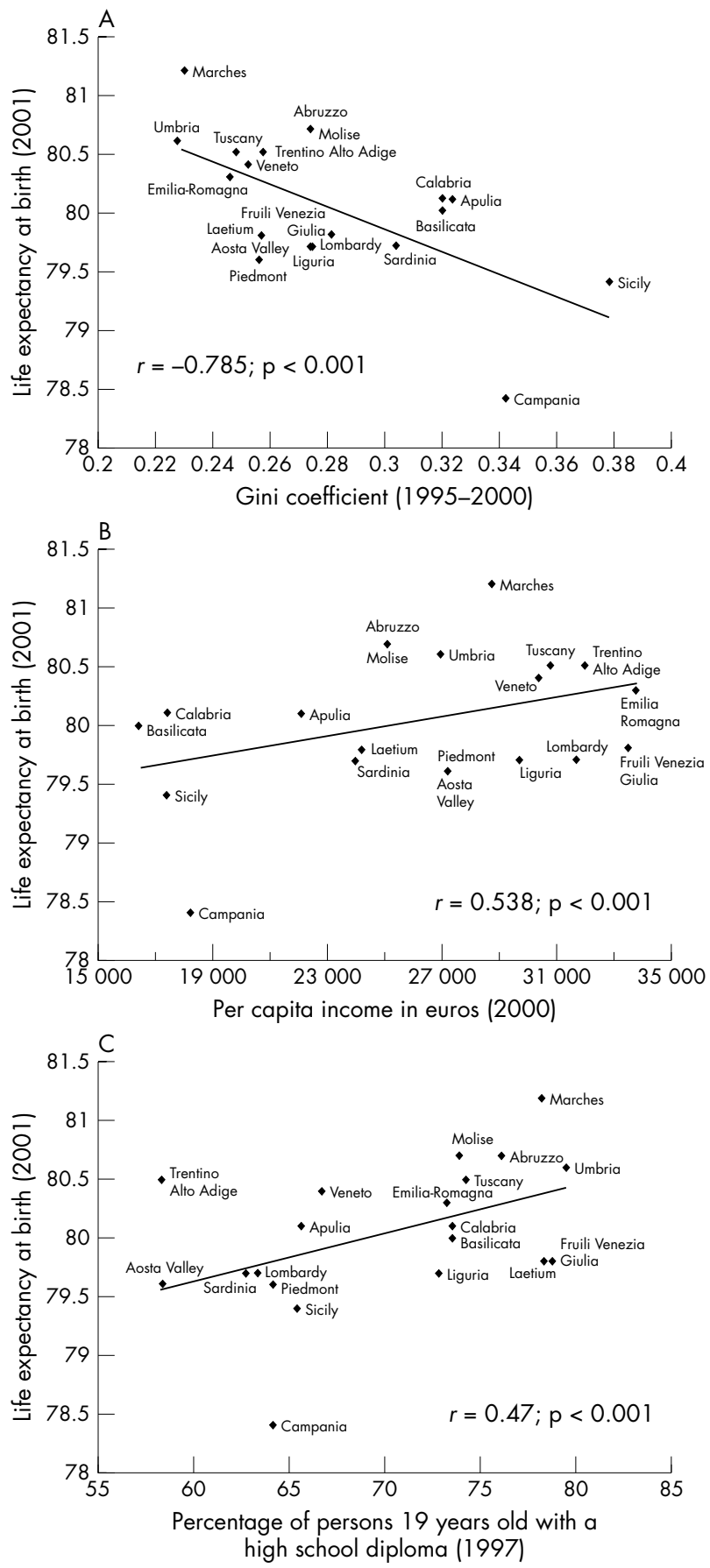

Figure 1 (A) Income inequality and life expectancy at birth among Italian regions $(n=20)$. Data are weighted by population size and adjusted for gross domestic product per capita. $r$ (crude) $=0.607$; $\mathrm{p}<0.005$. $r$ (adjusted for per capita income) $=-0.934 ; \mathrm{p}<0.011$. $r$ (weighted by population size) $=0.658 ; p<0.001$. (B) Economic development and life expectancy at birth among Italian regions $(n=20)$. Data are weighted by population size. (C) Association between educational attainment and life expectancy at birth among Italian regions $(n=20)$. Data are weighted by population size.

capita income. ${ }^{31}$ Data on population size, life expectancy at birth, per capita GDP, and Gini coefficients across top industrialised nations are shown in table B (see appendix).

\section{Statistical analyses}

For analyses within Italy, Pearson correlation coefficients were calculated to measure the association between life 
Table 1 Linear regression on life expectancy at birth across Italian regions $(n=20)$

\begin{tabular}{|c|c|c|c|c|c|c|c|}
\hline & \multicolumn{7}{|c|}{ Standardised $\beta$ coefficients } \\
\hline & Model 1 & Model 2 & Model 3 & Model 4 & Model 5 & Model 6 & Model 7 \\
\hline Gini index & $-0.658^{* * *}$ & - & - & $-0.785^{* * *}$ & $-0.559^{* * *}$ & - & $-0.443^{* * *}$ \\
\hline $\begin{array}{l}\text { Per capita } \\
\text { income }\end{array}$ & - & $0.538^{* \star *}$ & - & $-0.146^{*}$ & - & $0.496^{* * *}$ & 0.121 \\
\hline Education & - & - & $0.476^{* * *}$ & - & $0.276^{* \star *}$ & $0.426^{* * *}$ & $0.306^{* * *}$ \\
\hline Constant & 82.652 & 78.287 & 76.315 & 83.616 & 80.187 & 75.259 & 79.126 \\
\hline & 0.433 & 0.290 & 0.226 & 0.438 & 0.500 & 0.469 & 0.502 \\
\hline \multirow{2}{*}{$\begin{array}{l}\text { Model statistics: } \\
F(d f, N)\end{array}$} & & & & & & & \\
\hline & $363.9^{* \star *}(1,20)$ & $194.3^{* * *}(1,20)$ & $139.4^{* * *}(1,20)$ & $185.4^{* * *}(2,20)$ & $237.5^{\star \star \star}(2,20)$ & $210.5^{* * *}(2,20)$ & $159.8^{* * *}(3,20)$ \\
\hline
\end{tabular}

expectancy at birth and income inequality, per capita income, and educational attainment. Multivariate linear regression was used to study the relation between income inequality and life expectancy when adjusting for per capita income and educational attainment. Problems of collinearity could have arisen because of the high correlation between income inequality and per capita income $(r=-0.851 ; \mathrm{p}<0.001)$. As an indicator of collinearity, we used variance inflation factor (VIF) values greater than or equal to $10,{ }^{32}$ however in none of the multivariate regression models did the VIF exceed this threshold.

For analyses between countries, Pearson correlation coefficients adjusted for GDP per capita were calculated to measure the association between life expectancy at birth and income inequality.

All analyses were weighted by population size.

\section{RESULTS}

Figure 1A shows the relation between the Gini coefficient and life expectancy at birth across Italian regions. Income inequality had a strong negative correlation with life expectancy $(r=-0.785 ; \mathrm{p}<0.001)$. Regions whose income inequality was higher, such as Campania and Sicily, had a significantly lower life expectancy than regions where income inequality was comparatively low, for example, Marches and Umbria.

There were large variations among Italian regions in terms of per capita income (fig 1B), which ranged from $€ 16492$ for Basilicata to $€ 33774$ for Emilia-Romagna. ${ }^{28}$ Per capita income was positively correlated with life expectancy at birth $(r=0.538, \mathrm{p}<0.001)$. Regions with low per capita income such as Sicily and Campania had significantly lower life expectancy at birth compared with regions whose per capita income was high such as Emilia-Romagna, Trentino Alto Adige, and Tuscany.

Educational attainment was also positively correlated with life expectancy at birth $(r=0.476$; $\mathrm{p}<0.001$; fig $\mathrm{lC})$. Regions with a higher proportion of persons 19 years old having a high school diploma performed better in terms of life expectancy compared with regions where a lower proportion of young adults of the same age has a high school diploma.

Table 1 shows the results from multivariate linear regressions. The Gini coefficient by itself explained $43.3 \%$ of the variation in life expectancy at birth (model 1). When per capita income was introduced into the regression (model 4), the strength of the association between the Gini coefficient and life expectancy increased. The fit of the regression model improved, as shown by the increase in the adjusted $r^{2}$ from $43.3 \%$ (model 1) to $50.0 \%$ (model 5), when educational attainment was added to model with the Gini coefficient. Per capita income and educational attainment together explained $46.9 \%$ of the variance on life expectancy (model $6)$. When all three explanatory factors were included into the multiple regression analysis, the $\beta$ coefficient for per capita income was not significant while the coefficient for income

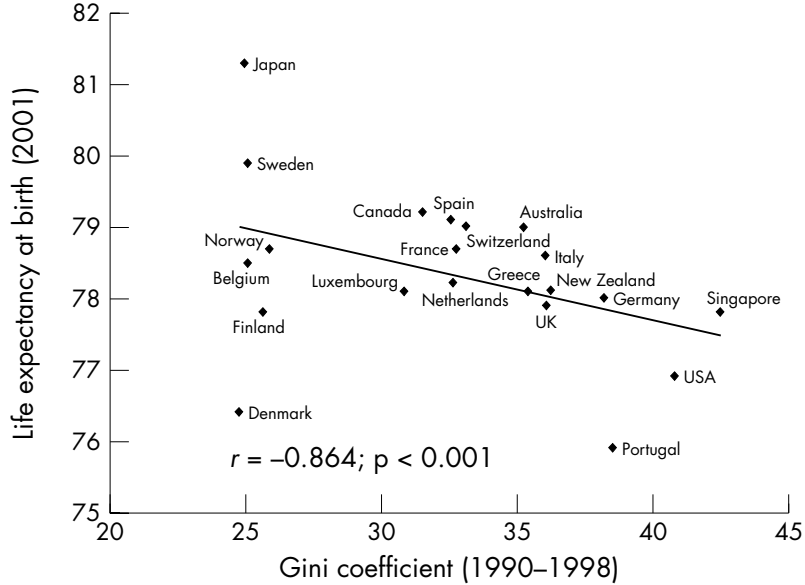

Figure 2 Income inequality and life expectancy at birth among industrialised countries $(n=21)$. Data are from the human development indicators 2003. The correlation presented in the figure is weighted by population size and adjusted for per capita gross domestic product (GDP). $r$ (crude) $=0.415 ; \mathrm{p}<0.65$. $r$ (adjusted for per capita GDP = $-0.433 ; \mathrm{p}<0.065$. $r$ (weighted by population size) $=-0.907$; $\mathrm{p}<0.001$.

inequality remained strongly associated with life expectancy $(\beta=-0.443 ; \mathrm{p}<0.001 ;$ model 7$)$. Moreover, the adjusted $r^{2}$ increased only slightly.

Figure 2 is a scatterplot of data on the Gini coefficient and life expectancy at birth across the top 21 industrialised countries, including Italy. ${ }^{30}$ Income inequality was strongly negatively correlated with life expectancy at birth $(r=-0.864 ; \mathrm{p}<0.001)$. Among wealthy countries, Italy has a moderately high degree of income inequality $(\mathrm{Gini}=0.36)$ and an average life expectancy at birth ( 78.6 years).

\section{DISCUSSION}

This study has a number of important findings. The first set of findings pertains to the Italian context. In Italy, income inequality was associated with life expectancy at birth even when per capita income and education (that is, high school completion rate of persons 19 years old) were held constant. Per capita income did not explain the relation, but education did to a small extent. There was an independent effect of education, but not of per capita income, on life expectancy at birth. The second set of findings situates the data from Italy in an international context. It is a country with a moderately high degree of income inequality and an average life expectancy compared with other wealthy nations. Among these nations, income inequality was negatively associated with life expectancy at birth, which is consistent with earlier reports. ${ }^{136}$

Amid recent data supporting the contrary, ${ }^{14}{ }^{16-18}$ our findings support the relative income hypothesis, which states 


\section{Key points}

- Among Italian regions, income inequality has an independent and more powerful effect on life expectancy than per capita income and education. Per capita income does not account for the effect of income inequality on life expectancy while education plays a partial, but limited part in explaining the relation.

- Italy has a moderately high degree of income inequality and an average life expectancy compared with other wealthy countries.

- Data from the top 21 industrialised nations including Italy show that there is a strong negative relation between income inequality and life expectancy at birth.

that for regions with GNP per capita beyond US\$ 800010000 , health status is mainly affected by the spread of income. ${ }^{3}$ Conversely, the absolute income hypothesis asserting that health is primarily influenced by economic development, even in a comparatively rich nation, is not supported by the data on Italy. Income inequality explained most of the variation in life expectancy, and the effect of per capita income on life expectancy disappeared when controlling for income inequality. Regions such as Marches, Umbria, and Tuscany that are more equitable in terms of income distribution and enjoyed a higher life expectancy. On the other hand, highly inequitable regions such as Sicily and Campania performed quite poorly in terms of life expectancy.

Two major pathways of causation have been proposed for the effect income inequality exerts on health status: the material deprivation pathway and the psychosocial pathway. ${ }^{33}$ The material deprivation pathway states that income inequality is related to health through a combination of negative exposures and lack of resources held by individuals, along with systematic underinvestment across a wide range of human, physical, health, and social infrastructures (for example, education, health services, transportation, environmental controls, availability of good quality food, quality of housing, and occupational health regulations). ${ }^{33}$ The psychosocial pathway argues that income inequality affects health through individual perceptions of place in the social hierarchy producing negative emotions such as stress, shame, and distrust that are translated "inside" the body into poorer health via psycho-neuro-endocrine-immunological mechanisms and stress induced behaviours such as smoking and overeating. Simultaneously, perceptions of relative position and negative emotions are also translated "outside" the individual into antisocial behaviours such as homicides, traffic accidents, and reduced civic participation, which result in less social capital and social cohesion within the community. ${ }^{3}$

This study shows that income inequality is strongly associated with health in a country where health care and education are publicly funded with practically free access to all citizens, and unemployed people receive social benefits.

\section{Policy implications}

- In the Italian context, improving population health may not only require policies that promote economic development, but also those that reduce income inequality and increase educational attainment.

- To promote population health, governments of wealthy nations are advised to minimise income inequality.
Results, showing that education played a significant part in explaining the relation between income inequality and life expectancy, are partially consistent with the material deprivation hypothesis. Income inequality may be partially associated with poorer infrastructures and lack of resources among the most disadvantaged populations, especially in southern Italy. However, we did not find an independent effect of per capita income, yet an independent effect of income inequality predominates. In contrast with previous studies, ${ }^{2425}$ the effect of education was small and did not account for the relation between income inequality and health. This may suggest that income inequality may exert an influence through psychosocial mechanisms such as social stress, for example from the unequal distribution of power among citizens, lack of political participation, and social cohesion. However, this study was not equipped to investigate this. Rather than considering the two major pathways of causation (material deprivation and psychosocial stress) as mutually exclusive, our study suggests that a combination of the two pathways are at work. ${ }^{34}$

The results from analyses between wealthy countries corroborate previous evidence showing a significant correlation between income inequality and life expectancy. ${ }^{16}$ Countries having lower levels of income inequality such as Japan and Sweden enjoy a better health compared with countries with high levels of income inequality such as the USA and Portugal. These results, however, are in contrast with the evidence presented by Lynch and colleagues who concluded that the higher income inequality was not associated with lower life expectancies. ${ }^{4}$ They suggested that the relation had disappeared because of the higher number of countries in their study, in comparison with the analysis presented by Wilkinson in $1992 .^{3}$

Our findings indicate that with updated data and the inclusion of five additional top industrialised countries in the analysis the relation reappears. Inclusion of Greece, Japan, New Zealand, Portugal, and Singapore, which were excluded in the analysis conducted by Lynch and colleagues because of unavailability of data, ${ }^{4}$ may explain, at least partially, the difference in results. However, a sensitivity test showed that, when these countries were excluded from the analysis, there was a moderate correlation between income inequality and life expectancy (data not shown).

Discrepancies may also be attributable to the delayed effects of changes in income distribution on mortality rates. ${ }^{35}$ During the late 1980s and 1990s some countries (for example, United Kingdom and Finland) experienced changes in income distribution. The true effect on life expectancy of these changes may have been difficult to detect (especially in the oldest age groups) in 1990-93, the years when the life expectancy data used by Lynch and colleagues were collected. ${ }^{4}$

This study has several limitations. As shown in other research, the level of geographical aggregation influences the association between income inequality and health. At higher levels of aggregation it is easier to find independent effects of income inequality on health outcomes. ${ }^{22}$ We do not know whether or not the use of the Gini coefficient at lower geographical levels such as provinces or municipalities would have produced different results. However, the level of aggregation needs not to be too small to allow income distribution to exert an effect independent of individual income. $^{36}$ Further studies from Italy using measures of income distribution at lower levels of aggregation would be useful to clarify this point. Another limitation is that the cross sectional data used precludes investigating how changes in income inequality over time influence population health. It is true that inequalities can take time to show their effects, but northern Italy has been more equitable than southern Italy at least since the creation of the unified 
state- that is, as far as income inequalities are concerned the situation has not substantially changed when we compare different regions. This analysis may also incur "ecological fallacies" when interpreting aggregated data to make conclusions about individuals. ${ }^{37}$ Multilevel analyses using individual level data on income and aggregated data on income inequality within Italy may contribute in the confirmation or rejection of study findings. However, as income inequality is inherently a social concept, it may not be plausible, both from a theoretical and methodological viewpoint, to evaluate its effects at the individual level. Finally, our cross national results must be interpreted with caution because of the difference between the reference dates of the Gini coefficients. While most of the Gini coefficients were collected between 1994 and 1998, data for Switzerland, Japan, and Spain were from 1990 and 1993. Moreover, comparability problems remain in the use of data from household surveys across countries, even though these problems are diminishing as survey methodologies are improving and becoming more standardised. ${ }^{31}$

Despite the limitations, our research suggests that the relation between income inequality and population health among wealthy nations has not disappeared as claimed by some authors. ${ }^{413}$ Furthermore, using data from Italy, a country with a moderately high degree of income inequality among the industrialised nations, we show that, in contrast with studies from other countries, ${ }^{23-25}$ income inequality had an independent and more powerful effect on life expectancy at birth than per capita income and educational attainment. More research is needed to analyse the material and psychosocial mechanisms between income inequality and health in wealthy nations including Italy. However, despite which pathway of causation predominates, income inequality remains a key determinant of population health. Consequently, public policy and public health initiatives to reduce or contain such inequalities are essential to reach public health objectives at the population level.

\section{ACKNOWLEDGEMENTS}

We greatly appreciate the invaluable review and comments provided by Richard Wilkinson and George Davey Smith in the preparation of this manuscript.

\section{CONTRIBUTORS}

RD performed most of the analyses and wrote most of the paper. RM participated in the writing of the paper, reviewed its contents, and conducted some statistical analyses. RG inspired the development of research hypotheses, reviewed the paper, and participated in the interpretation of results. GAC participated in the design of the manuscript and inspired the framing of the paper.

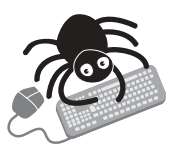

The appendix is available on line (http://www.jech. com/supplemental).

\section{Authors' affiliations}

R De Vogli, The University of California Los Angeles (UCLA), School of Public Health, USA

R Mistry, The University of California Los Angeles (UCLA), School of Public Health

R De Vogli, R Gnesotto, The Epidemiology Centre of the Veneto Region, Italy

G A Cornia, The University of Florence, Faculty of Economics, Italy

Funding: the work of RD and GAC was supported in part by the John D and Catherine T MacArthur Foundation Research Network Project on Socioeconomic Status and Health.

Competing interests: none declared.

\section{REFERENCES}

1 Rodgers G. Income and inequality as determinants of mortality: an international cross-sectional analysis. Population Studies 1979;33:343-51.

2 Waldman R. Income distribution and infant mortality. Quarterly Journal of Economics 1992;107:1283-302.

3 Wilkinson R. Unhealthy societies: the affliction of inequalities. London: Routledge, 1996.

4 Lynch JW, Davey Smith G, Hillemeier M, et al. Income inequality, the psychosocial environment and health: comparisons of wealthy nations. Lancet 2001;358:194-200

5 LeGrand J. Inequalities in health. Some international comparisons. European Economic Review 1987;31:182-91.

6 Wilkinson R. Income distribution and life expectancy. BMJ 1992;304:165-8.

7 Marmot M, Bobak M. International comparators and poverty and health in Europe. BMJ 2000;321:1124-8.

8 Davey Smith G, Egger M. Understanding it all-health, meta-theories, and mortality trends. BMJ 1996;313:1584-5.

9 Walberg P, McKee M, Shkolnikov V, et al. Economic change, crime, and mortality crisis in Russia: regional analysis. BMJ 1998;317:312-18.

10 Kaplan G, Pamuk ER, Lynch JW, et al. Inequality in income and mortality in the United States: analysis of mortality and potential pathways. BMJ 1996;312:999-1003

11 Kennedy B, Kawachi I, Prothrow D. Income distribution and mortality: crosssectional ecological study of the Robin Hood Index in the United States. BMJ 1996:312:1004-7.

12 Ben Shlomo Y, White I, Marmot M. Does the variations in the socioeconomic characteristic of an area affect mortality. BMJ 1996;312:1013-14.

13 Mackenbach JP. Income inequality and population health: evidence favouring a negative correlation between income inequality and life expectancy has disappeared. BMJ 2002;324:1-2.

14 Ross NA, Wolfson M, Dunn JR, et al. Relation between income inequality and mortality in Canada and in the United States: cross sectional assessment using census data and vital statistics. BMJ 2000;320:898-902.

15 Sanmartin C, Ross NA, Tremblay S, et al. Labour market income inequality and mortality in North American metropolitan areas. J Epidemiol Community Health 2003;57:792-7.

16 Osler M, Prescott E, Gronbaek M, et al. Income inequality, individual income, and mortality in Danish adults: analysis of pooled data from two cohort studies. BMJ 2002;324:1-4

17 Shibuya K. Individual income, income distribution, and self rated health in Japan: cross sectional analysis of nationally representative sample. BMJ 2002;324:1-5

18 Blakely T, Atkinson J, O'Dea D. No association of income inequality with adult mortality within New Zealand: a multi-level study of 1.4 million 25-64 year olds. J Epidemiol Community Health 2003;57:279-84.

19 Gravelle H. How much of the relation between population mortality and unequal distribution of income is a statistical artefact? BMJ 1998;316:382-5.

20 Wolfson M, Kaplan G, Lynch JW, et al. Relationship between income inequality and mortality: empirical demonstration. BMJ 1999;319:953-7.

21 Daly M, Duncan G, Kaplan GA, et al. Macro-to-micro linkages in the inequality-mortality relationship. Milbank Mem Fund Q 1998;76:315-39.

22 Soobader M, LeClere F. Aggregation and the measurement of income inequality: effects on morbidity. Soc Sci Med 1999;48:733-44.

23 Fiscella K. Poverty or income inequality as predictor of mortality: longitudinal cohort studies. BMJ 1997;314:1724.

24 Muller A. Education, income inequality and mortality: a multiple regression analysis. BMJ 2002;324:23-5.

25 Messias E. Income inequality, illiteracy rate, and life expectancy in Brazil. Am J Public Health 2003;93:1294-6.

26 Cannari L, D'Alessio G. La distribuzione del reddito e della ricchezza nelle regioni Italiane. Rome: Banca d'Italia, 2003.

27 ISTAT. Indicatori Demografici. Rome: Istituto Nazionale di Statistica, 2003. http://demo.istat.it/ind_dem2002.htm (accessed 10 Jan 2003).

28 Banca d'Italia. Survey on Italian households wealth and income (SIHWI). Rome: Banca d'Italia, 2003.

29 ISTAT. Indicatori Sociosanitari, 1997. Rome: Istituto Nazionale di Statistica, 1998.

30 UNDP. Human Development Report 2003. New York: Oxford University Press, 2003.

31 World Bank. World Development Indicators, 2003 [CD ROM]. Washington, DC: World Bank, 2003.

32 Belsley D. Conditioning diagnostics: collinearity and weak data in regression. New York: Wiley, 1991

33 Lynch JW, Davey Smith G, Kaplan GA, et al. Income inequality and mortality: importance to health of individual income, psychosocial environment, or material conditions. BMJ 2000;320:1200-4

34 Wilkinson R. Two pathways, but how much do they diverge? BMJ 1999;319:956-7.

35 Lobmayer $\mathbf{P}$, Wilkinson R. Income inequality and mortality in 14 developed countries. Sociology of Health and Illness 2000;22:401-14.

36 Kennedy B, Kawachi I, Glass R, et al. Income distribution, socioeconomic status and self-rated health in the United States: multilevel analysis. BMJ 1998;317:917-21.

37 Gravelle H. Diminishing returns to aggregate level studies. BMJ 1999;319:955-6. 


\section{PostScript}

\section{BOOK REVIEWS}

\section{Global behavioral risk factor surveillance}

Edited by $D$ McQueen, $P$ Puska. Kuwer Academics/Plenum, 2003, \$65.00, pp 255. ISBN 0-306-47777-7

This book is a godsend to those working in the area of monitoring and understanding changes overtime in chronic disease risk factors. It is a collection of 18 chapters authored by experts around the world and provides a comprehensive insight into establishing and maintaining the surveillance of behavioural risk factors both in developed and developing countries.

The examples of behavioural risk factor surveillance systems in a variety of international settings provide not only a glimpse into the diversity of issues but also suggest creative solutions to these challenges. Furthermore, what makes this book a practical public health resource are topics such as analysis, interpretation, comparison, and use of behavioural risk factor surveillance data. This book will serve as a guide for those new to chronic disease surveillance but there is plenty here for the seasoned public health professionals looking to hone their skills. I was pleased to see the reporting of the essence of the discussions that occurred at the four global meetings on risk factor surveillance attended by international community members beginning in 1999.

The authors have successfully shown that the global burden of disease is changing and chronic diseases are important health problems in industrialised as well as developing countries. This shift calls for urgency and action to create an applied global surveillance system that would permit comparison of chronic disease risk factor trends, similarities, and experiences across populations. Surveillance of chronic disease risk factors is essential in planning and evaluating disease prevention and health programmes and policies.

\section{Qaiser Mukhtar}

\section{Oxford textbook of public health, 4th ed}

Edited by $R$ Detels, J McEwen, R Beaglehole, H Tanaka. Oxford: Oxford University Press, 2002, pp 1955.

The paperback edition of the Oxford Textbook of Public Health has in one volume the same contents as the hardback edition of 2002. The price is a clear advantage over the hardback edition, less than one third of the latter, making the book affordable for practitioners and students.

Compared with the hardback edition, there is nothing new in the contents of this edition. The volumes of the hardback edition are sections in this one volume edition. The first section presents the scope of public health (22 chapters in four parts), the second introduces the methods of public health (38 chapters in four parts), and the third details the practice of public health (41 chapters in four parts).

This book is an up to date text on the important topics of public health. It deals with emerging and re-emerging infectious diseases (although SARS is not featured as the contents date from 2002), the challenge of globalisation, and how to solve social inequalities in health. Ethics is given the detail it deserves, in relation to human rights. Some complex and difficult issues are adequately discussed: how to prioritise public health problems, how to identify and carry out cost effective strategies, and the resolution of public health problems not from a disease oriented approach but from a more comprehensive point of view.

In summary, this textbook continues to be an excellent reference for public health practitioners, teachers, and students.

Miguel Delgado-Rodríguez

\section{CORRECTIONS}

doi: 10.1136/jech.2004.020651

Three editorial errors occurred in this paper by Dr R De Vogli and others (2005;59:15862 ). In the third line of the legend to figure 1 it should read $r$ (crude) $=-0.607$ [not 0.607]. In the fifth line of the legend to figure 1 it should read $r$ (weighted by population size) $=-0.658$ [not 0.658]. In the fifth line of the legend to figure 2 it should read $r$ (crude) $=-0.415$ [not 0.415 ].

\section{doi: 10.1136/jech.2003.019547corrl}

An authors' error occurred in this paper by Dr J Doyle and others (2005;59:193-7). Dr Kwok Cho Tang from the World Health Organisation, Geneva was omitted from the author list.

\section{bmjupdates+}

bmjupdates+ is a unique and free alerting service, designed to keep you up to date with the medical literature that is truly important to your practice.

bmjupdates + will alert you to important new research and will provide you with the best new evidence concerning important advances in health care, tailored to your medical interests and time demands.

Where does the information come from? bmjupdates+ applies an expert critical appraisal filter to over 100 top medical journals A panel of over 2000 physicians find the few 'must read' studies for each area of clinical interest

Sign up to receive your tailored email alerts, searching access and more...

www.bmjupdates.com 